\title{
Leaf-surface wax of desert plants as a potential lubricant additive
}

\author{
Yanqiu XIA ${ }^{1, *}$, Xiaochun XU ${ }^{1}$, Xin FENG ${ }^{1}$, Guoxiong CHEN $^{2, *}$ \\ ${ }^{1}$ School of Energy Power and Mechanical Engineering, North China Electric Power University, Beijing 102206, China \\ ${ }^{2}$ Key Laboratory of Stress Physiology and Ecology in Cold and Arid Regions, Cold and Arid Regions Environmental and Engineering \\ Research Institute, Chinese Academy of Sciences, Lanzhou 730000, China
}

Received: 09 February 2015 / Revised: 03 April 2015 / Accepted: 17 April 2015

(C) The author(s) 2015. This article is published with open access at Springerlink.com

\begin{abstract}
Using an MFT-R4000 tester at room temperature, the leaf-surface wax of two desert plants, Ammopiptanthus mongolicus (AM) and Reaumuria soongorica (RS), was extracted and evaluated for its potential as a lubricant additive in polyalphaolefin (PAO) for steel-steel contact. Gas chromatography-mass spectrometry analysis was performed to identify the composition of the AM leaf-surface wax, and scanning electron microscopy and X-ray photoelectron spectroscopy were used to investigate its friction mechanisms. The results suggest that the leaf-surface wax could successfully reduce the friction and wear of steel-steel sliding pairs compared with PAO containing molybdenum dithiocarbamate additives. AM, in particular, showed high-performance wear resistance and friction-reducing properties. Its excellent tribological properties were attributed to the wax composition of leaf-surface fatty acids, alcohol, and esters.
\end{abstract}

Keywords: leaf-surface wax; Ammopiptanthus mongolicus; lubricant additive; friction and wear

\section{Introduction}

Lubricant additives are chemical compounds used with base oils to improve lubricant performance and longevity. Almost all commercial lubricants contain these additives, which can eliminate corrosive, abrasive, and adhesive wear, as well as the wear of mechanical parts due to contact fatigue. Commercial lubricants typically contain one or more additives mixed with one or several base oils. Additives including molybdenumcontaining organic compounds and zinc dithiophosphate (ZDDP) have been employed to enhance the performance characteristics of the base oil. Some types of additives facilitate only one aspect of lubricant performance. For example, an extreme pressure additive allows a lubricant to attain high load-carrying capacity. Other types of additives such as ZDDP facilitate multiple aspects of lubricant performance, including

*Corresponding author: Yanqiu XIA; Guoxiong CHEN.

E-mail: xiayq@ncepu.edu.cn; guoxiong@1zb.ac.cn wear protection and oxidation inhibition. In most commercial products, a mixture of components is included in an additive package, which is then mixed with the base oil. Traditional additives, including ZDDP, which contain S, P, or ash are known to be harmful to the environment. Therefore, there is a growing trend to develop non-toxic and environmentally friendly non-S, $\mathrm{P}$, and ash additives.

Organic borate esters are regarded as promising lubricant additives because of their relative non-toxicity, good biodegradability, and pleasant odor [1]. Ren et al. $[2,3]$ found that novel borate esters contain only $H$, $\mathrm{C}, \mathrm{O}, \mathrm{N}$, and $\mathrm{B}$ elements and have high anti-wear and extreme pressure properties. Zhang et al. [4] studied the friction and wear properties of benzoic acid, benzoic alcohol, benzaldehyde, ethyl benzoate, and acelophenone as additives in liquid paraffin using a four-ball machine. Martin and Matta [5] found that the use of unsaturated fatty acid as an additive can reduce the friction and wear of diesel fuels. Anastopoulos et al. [6] found seven di-carboxylic acid esters to be suitable for 
increasing kerosene lubricity. The use of palm fatty acids in commercial metal forming oil was shown to decrease the frictional coefficient from 0.08 to 0.054 , indicating that palm fatty acids have the potential to enhance lubricant performance [7]. Kano et al. [8] found that ta-C leads to a super-low regime with oleic acid. These references all show that the use of acids, alcohols, and esters as additives can reduce friction in lubricants and improve their wear resistance.

Organic compounds such as molybdenum dithiocarbamate (MoDTC) are popular for use as lubricant additives because of their excellent friction-reducing properties, wear resistance, anti-oxidant characteristics, and load carrying capacities. The mechanism underlying the friction reduction property in additives containing Mo is ascribed to the adsorption of MoDTC by the frictional surfaces and the formation of $\mathrm{MoS}_{2}$ [9-13]. It is the $\mathrm{MoS}_{2}$ layer lattice structure that leads to lower friction. $\mathrm{MoS}_{2}$ is characterized by strong covalent bonding between atoms but weak Van der Waals attraction between its lattice layers. These weak Van der Waals forces maintain an easy shearing in the molecules, which results in its low-friction properties [13]. Therefore, MoDTC is known for its exceptional friction reduction and wear resistance properties.

Leaf-surface wax is prevalent in plants. Hydrophobic wax, including fatty acids (C16 to C36) and their relatives such as alkanes, alcohols, and esters, have been extracted from eucalyptus, lupin, and lucerne in non-wet sand conditions [14]. Cornelia et al. [15] found that the leaves of the castor bean contain alkanes, alcohols, aldehydes, fatty acids, and triterpenoids. Ji and Jetter [16] investigated alkylresorcinol localization in the layers of rye leaf cuticular wax and found that the total wax load of both leaf surfaces contained about $71 \%$ primary alcohols, $11 \%$ alkyl esters, $5 \%$ aldehydes, and less than $3 \%$ other components. Xu et al. [17] investigated the composition of the cuticular wax of the desert moss Syntrichia caninervis and revealed that fatty acids, alcohols, and alkanes were its major chemical constituents.

Ammopiptanthus mongolicus (AM) and Reaumuria soongorica (RS) are evergreen and deciduous shrubs, respectively. They are remnants of the tertiary period and are distinctively dispersed in northwestern China, which is characterized by intense drought stress and extremely high temperatures in summer $\left(>40^{\circ} \mathrm{C}\right)$, low temperatures in winter $\left(<-30^{\circ} \mathrm{C}\right)$, meager soils, high salinity, and unusually high ultraviolet irradiation. As such, one may infer that the leaf-surface wax of these shrubs has strong protective features. Plant leaf-surface wax is mostly a mixture of very long-chain aliphatics (C20-C60) and some secondary metabolites, including flavonoids, phenylpropanoids, and triterpenoids [18].

In this study, we used the leaf-surface wax from the two desert plants to investigate its potential as a lubricant additive in polyalphaolefin (PAO) and evaluated its effects in reducing friction and improving wear resistance in steel-steel sliding pairs.

\section{Experimental procedure}

\subsection{Wax extraction and lubricating oil preparation}

AM (Fig. 1) and RS (Fig. 2) plant samples were collected in Shapotou, Ningxia (northwest China). Before extracting the leaf-surface wax, the leaves were cleaned, dried, and then immersed once for 10-30 s in chloroform at room temperature. The liquids were then dried, filtered, and concentrated to yield wax (solid powder). We used a gas chromatography-mass spectrometry (GC-MS) analysis system to determine the composition of the AM leaf wax. Next, the leaf-surface wax samples were prepared for use as lubricant additives in the experiment. The AM and RS leaf-surface wax samples were dissolved in PAO at a ratio of $2.0 \%(w / w)$ by ultrasonic vibration. The reference PAO lubricant contained about $0.5 \%$ of MoDTC (Adahi Denka Company, Japan). For the base oil, we purchased synthetic PAO with nominal $100{ }^{\circ} \mathrm{C}$ and $40{ }^{\circ} \mathrm{C}$ kinematic viscosities of 4 and $16.81 \mathrm{cSt}$, respectively, from Exxon Modile Corporation (Irving, TX, USA).

\subsection{Friction and wear test}

To evaluate the tribological behavior of these leafsurface wax additives for steel-steel contact, friction and wear tests were performed with an MFT-R4000 (Lanzhou, China) reciprocating friction and wear tester, with a ball-on-disks configuration. The upper AISI 52100 steel ball had a hardness of $710 \mathrm{HV}$ and a diameter of $3 \mathrm{~mm}$, and the slides were reciprocal at an amplitude of $5 \mathrm{~mm}$ against motionless lower steel 


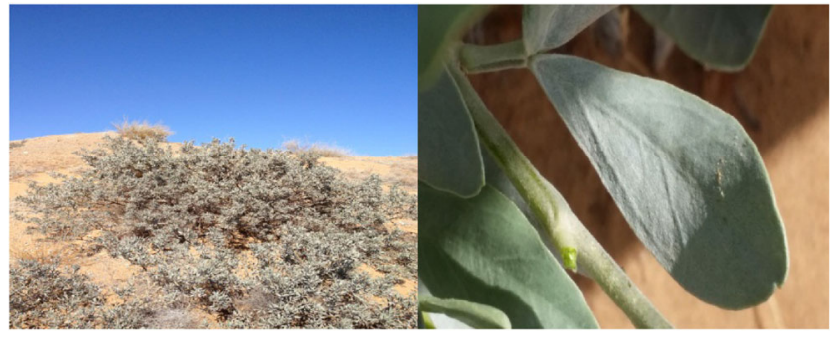

Fig. 1 The Ammopiptanthus mongolicus and leaves.

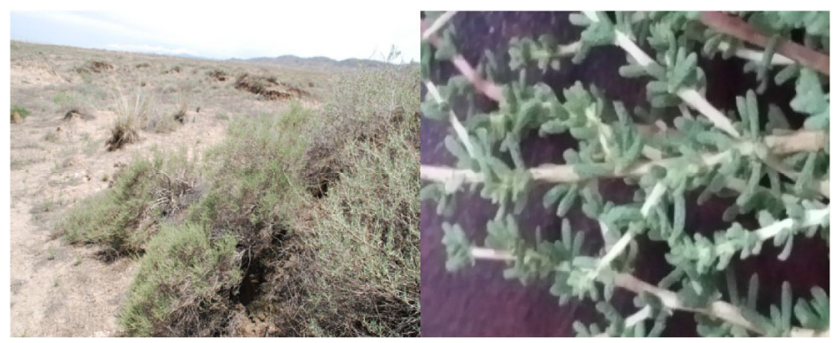

Fig. 2 Leaves of the Reaumuria soongorica and leaves.

disks (AISI 52100 steel, $\Phi 24 \mathrm{~mm} \times 7.9 \mathrm{~mm}$ with a hardness of 720-760 HV). The friction and wear tests were conducted at a frequency of $5 \mathrm{~Hz}$, for a duration of $30 \mathrm{~min}$ at room temperature. All investigations were conducted under a load of $100 \mathrm{~N}$ (at a mean contact pressure of about $3.25 \mathrm{GPa}$ ). The experiment under each set of conditions was replicated three times to estimate experimental errors. At the end of each experiment, the width of the wear scars on the lower disk was measured with an optical microscope at an accuracy of $0.01 \mathrm{~mm}$.

\subsection{Characterization of the worn surface}

A JSM-5600LV scanning electron microscope (SEM) was used to analyze the morphology of the worn steel surfaces. An X-ray photoelectron spectrometer (XPS) was used to identify the chemical states of the main elements on the worn surfaces of the steel discs, where the excitation source was $\mathrm{Mg}-\mathrm{Ka}$ radiation and the reference was the binding energy of contaminated carbon $\left(\mathrm{C}_{1 \mathrm{~s}}: 284.8 \mathrm{eV}\right)$.

\section{Results and discussion}

\subsection{AM leaf-surface wax components}

Table 1 lists the AM leaf-surface wax components from the GM analysis results. Non-polar alkanes accounted for $46.5 \%$ of the AM leaf-surface wax components, and the polar fraction accounted for $23.7 \%$, including fatty acids, alcohol, ketones, esters, and three pentacyclic triterpene alcohols (Table 1).

\subsection{Tribological properties}

Figure 3 shows the friction coefficients of the sliding pairs under PAO lubrications containing 2\% AM, 2\% $\mathrm{RM}$, and $0.5 \% \mathrm{MoDTC}$ at $100 \mathrm{~N}$ and a frequency of $5 \mathrm{~Hz}$ at room temperature. When the base oil (PAO) was used as the lubricant, the coefficients of friction showed the highest values. The frictional coefficient of the

Table 1 Part compounds in the leaf wax of AM identified by GC-MS.

\begin{tabular}{|c|c|c|c|c|}
\hline & & Molecular formula & Molecular weight & Compound \\
\hline \multirow{3}{*}{$\begin{array}{l}\text { Non-polar } \\
\text { alkanes } \\
\text { accounted for } \\
46.5 \%\end{array}$} & \multirow{3}{*}{ Alkane } & $\mathrm{C}_{23} \mathrm{H}_{48}$ & 324 & Tricosane \\
\hline & & $\mathrm{C}_{28} \mathrm{H}_{58}$ & 394 & 3-methyl-heptacosane \\
\hline & & $\mathrm{C}_{32} \mathrm{H}_{66}$ & 450 & Dotriacontane \\
\hline \multirow{9}{*}{$\begin{array}{l}\text { Polar fraction } \\
\text { accounted for } \\
23.7 \%\end{array}$} & \multirow{3}{*}{ Acid } & $\mathrm{C}_{10} \mathrm{H}_{20} \mathrm{O}_{2}$ & 172 & Decanoic acid \\
\hline & & $\mathrm{C}_{13} \mathrm{H}_{26} \mathrm{O}_{2}$ & 214 & Tridecanoic acid \\
\hline & & $\mathrm{C}_{18} \mathrm{H}_{36} \mathrm{O}_{2}$ & 284 & Octadecanoic acid \\
\hline & \multirow{3}{*}{ Ester } & $\mathrm{C}_{17} \mathrm{H}_{34} \mathrm{O}_{2}$ & 270 & Hexadecanoic acid, methyl ester \\
\hline & & $\mathrm{C}_{24} \mathrm{H}_{48} \mathrm{O}_{2}$ & 368 & Docosanoic acid, ethyl ester \\
\hline & & $\mathrm{C}_{36} \mathrm{H}_{72} \mathrm{O}_{2}$ & 536 & Dodecanoicacid, tetracosyl ester \\
\hline & \multirow{3}{*}{ Alcohol } & $\mathrm{C}_{16} \mathrm{H}_{34} \mathrm{O}$ & 242 & Hexadecan-1-ol \\
\hline & & $\mathrm{C}_{19} \mathrm{H}_{40} \mathrm{O}$ & 284 & Nonadecan-1-ol \\
\hline & & $\mathrm{C}_{27} \mathrm{H}_{56} \mathrm{O}$ & 396 & 2-methyl-hextacosan-1-ol \\
\hline
\end{tabular}



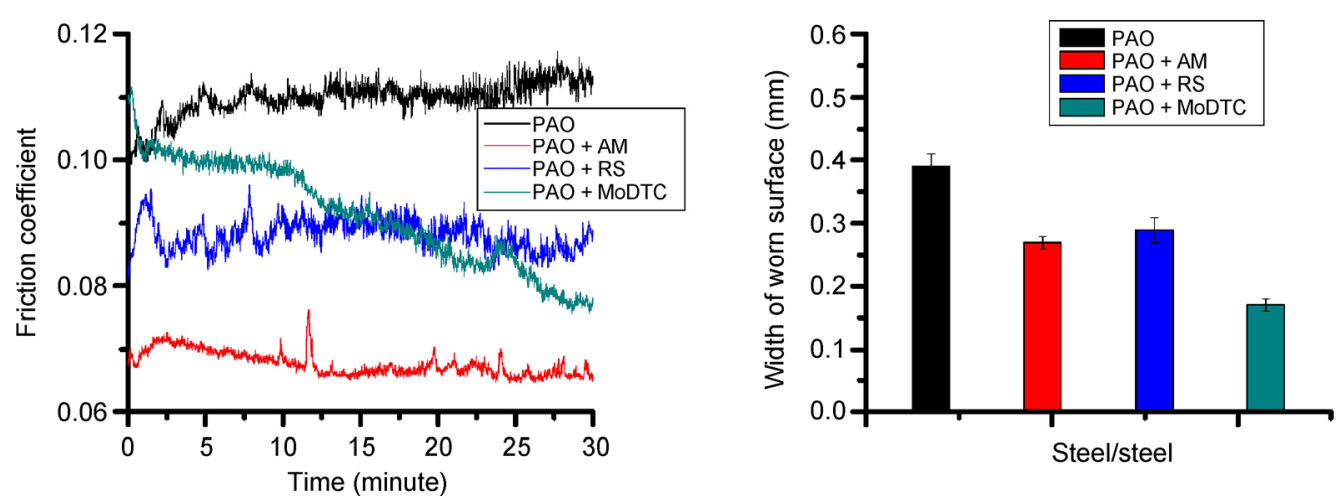

Fig. 3 Friction coefficient and width of worn surface of different additives in PAO (100 N, $5 \mathrm{~Hz}, 30 \mathrm{~min})$ for the contact of steel/steel.

PAO containing $0.5 \%$ MoDTC gradually decreased from about 0.112 to 0.076 . The AM-containing lubricant was stable and had the lowest frictional coefficient, 0.068, throughout the whole friction and wear test process. The RM-containing lubricant had a higher frictional coefficient than that of AM but lower than that of MoDTC. The two leaf-surface extracts exhibited lower frictional coefficients than the MoDTC, which is widely used as a friction modifier in lubricants. The general trend of the frictional coefficients observed for the steel-steel contact was as follows: AM $<$ RS $<$ MoDTC $<$ PAO. These data indicate that the two leafsurface extracts, when used as additives, exhibited excellent friction-reduction performance for steel-steel contact.

The width of the worn surfaces lubricated with various lubricant additives for steel-steel contact increased as follows: MoDTC $<\mathrm{AM}<\mathrm{RS}<\mathrm{PAO}$ (Fig. 3). The width of the worn surface lubricated by MoDTC was the narrowest. This result indicates that the two leaf extracts contributed to a reduction in wear as compared with the reduction achieved when using basic PAO oil.

\subsection{Surface analysis}

Figure 4 shows SEM micrographs of the worn steel surfaces lubricated with PAO only and PAO containing $2 \%$ AM, $2 \%$ RS, and $0.5 \%$ MoDTC as additives (100 N, $30 \mathrm{~min}$ ). The PAO-only surfaces showed signs of slight adhesive wear with relatively wide grooves (Fig. 4(a)). The wear scars had relatively narrow grooves for the surfaces lubricated with the PAO containing AM and RS as additives (Figs. 4(b) and 4(c)). The worn surfaces of the steel lubricated by MoDTC showed very similar features to those of surface polishing (Fig. 4(d)). From this experiment it is inferred that the extracts from the leaves of AM and RS possess excellent tribological properties and have good potential as lubricant additives.

XPS analysis was used to further clarify the chemical states of several main elements on the steel surface and of the boundary film formed on the steel wear scar surfaces that were lubricated with AM. The XPS results showed spectra in the $\mathrm{C}_{1 \mathrm{~s}}, \mathrm{O}_{1 \mathrm{~s}}$, and $\mathrm{Fe}_{2 \mathrm{p}}$ regions (Fig. 5). The peak of $\mathrm{C}_{1 \mathrm{~s}}$ appears at a binding
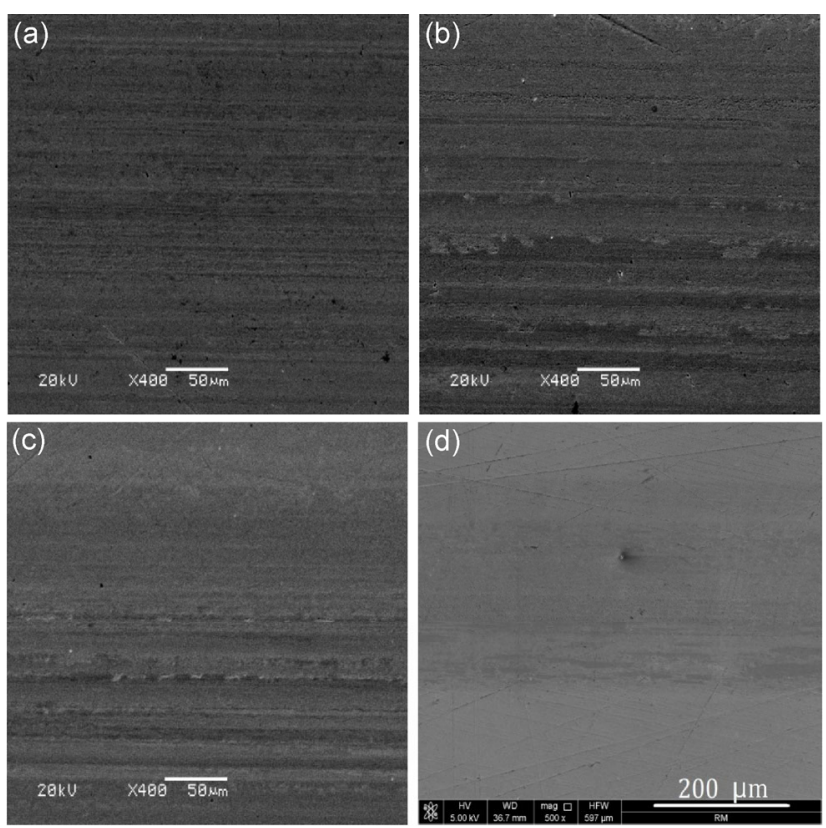

Fig. 4 SEM images of the worn surfaces lubricated by different additives: PAO (a), AM (b), RS (c), and MoDTC (d) in steel/steel pairs $(100 \mathrm{~N}, 5 \mathrm{~Hz}, 30 \mathrm{~min})$. 

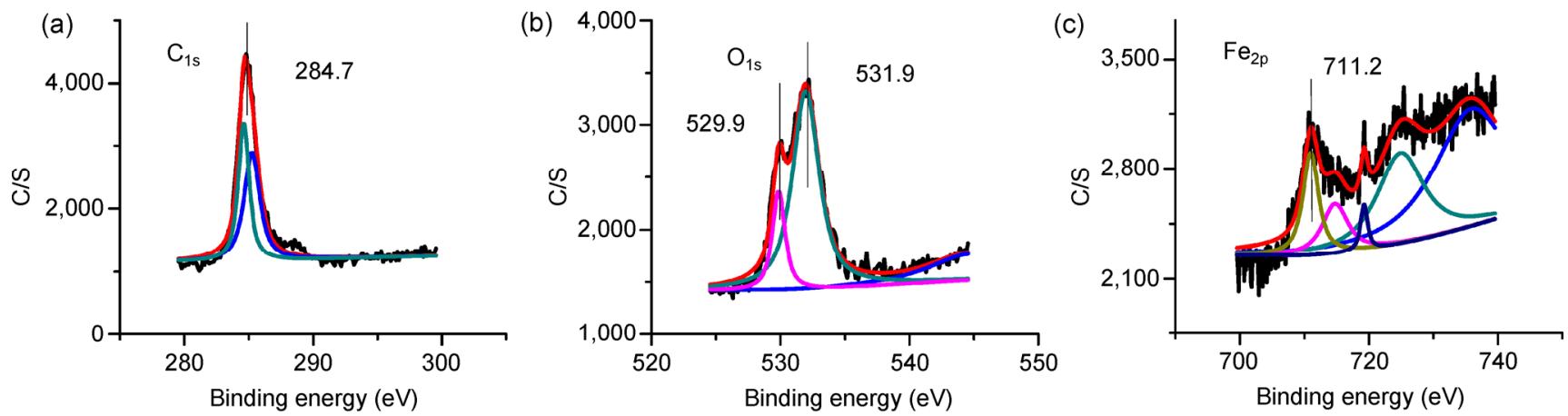

Fig. 5 XPS of spectra of $\mathrm{C}_{1 \mathrm{~s}}(\mathrm{a}), \mathrm{O}_{1 \mathrm{~s}}$ (b), and $\mathrm{Fe}_{2 \mathrm{p}}$ (c) on the rubbed surface of steel block lubricated with Ammopiptanthus mongolicus.

energy from 284.4 to $285.3 \mathrm{eV}$, which was identifiable as $\mathrm{C}$ in polymerized ester (Fig. 5(a)) [19]. $\mathrm{O}_{1 \mathrm{~s}}$ showed XPS peaks at binding energies of 529.9 and $531.9 \mathrm{eV}$, which were identifiable as metal oxides and hydroxides, respectively (Fig. 5(b)) [20]. The binding energy of $\mathrm{Fe}_{2 \mathrm{p}}$ at $711.2 \mathrm{eV}$ is attributed to either $\mathrm{FeO}, \mathrm{Fe}_{3} \mathrm{O}_{2}$, or $\mathrm{Fe}_{3} \mathrm{O}_{4}$ (Fig. 5(c)) [19]. These results reveal complicated tribochemical reactions during the friction process, including the generation of surface protective films composed of polymerized ester and metal oxides on the lubricated metal surface, which lead to reduced friction and wear between the rubbing pairs.

\section{Conclusion}

Results from this study show that the use of leaf-surface wax from the desert plants AM and RS played an important role in improving the tribological properties of lubricants. On the basis of these results, we consider that they could significantly reduce friction and wear in steel-steel contacts. The excellent tribological properties of the leaf-surface wax are attributed to its organic composition, including acids, alcohol, and esters. Because of the superior tribological properties and environmentally friendly advantages of leafsurface wax from the AM and RS desert plants, we propose that they might be attractive alternatives to some conventional lubricant additives.

\section{Acknowledgments}

The authors would like to thank the financial support for this work from the National Natural Science Foundation of China (No. 51575181).
Open Access: This article is distributed under the terms of the Creative Commons Attribution License which permits any use, distribution, and reproduction in any medium, provided the original author(s) and source are credited.

\section{Reference}

[1] Choudhary R B, Pande P P. Lubrication potential of boron compounds: An overview. Lubr Sci 14: 211-22 (1965)

[2] Yan J, Zeng X, van der Heide E, Ren T. The tribological performance and tribochemical analysis of novel borate esters as lubricant additives in rapeseed oil. Tribol Int 71: 149-157 (2014)

[3] Li J, Li Z, Ren T, Zeng X, van der Heide E. Hydrolytic stability and tribological properties of N-containing heterocyclic borate esters as lubricant additives in rapeseed oil. Tribol Int 73: 101-110 (2014)

[4] Zhang J, Liu W M, Xue Q J. The friction and wear behaviors of some O-containing organic compounds as additives in liquid paraffin. Wear 219: 124-127 (1998)

[5] Martin J M, Matta C, Bouchet M D B, Forest C, Le Mogne T, Dubois T, Mazarin M. Mechanism of friction reduction of unsaturated fatty acids as additives in diesel fuels. Friction 1(3): 252-258 (2013)

[6] Anastopoulos G, Kalligeros S, Schinas P, Zannikos F. Effect of dicarboxylic acid esters on the lubricity of aviation kerosene for use in CI engines. Friction 1(3): 271-278 (2013)

[7] Syahrullail S, Hariz M A, Abdul Hamid M K, Abu Bakar A R. friction characteristic of mineral oil containing palm fatty acid distillate using four ball tribo-tester original. Pro Eng 68: 166-171 (2013)

[8] Kano M, Martin J M, Yoshida K, Yoshida K, DE Barros Bouchet M I. Super-low friction of ta-C coating in presence of oleic acid. Friction 2(2): 156-163 (2014) 
[9] Grossiord C, Varlot K, Martin J M, Le Mogne T, Esnouf C, Inoue $\mathrm{K} . \mathrm{MoS}_{2}$ single sheet lubrication by molybdenum dithiocarbamate. Tribol Int 31: 737-743 (1998)

[10] De Barros M I, Bouchet J, Raoult I, Mogne T L, Martin J M, Kasrai M, Yamada Y. Friction reduction by metal sulfides in boundary lubrication studied by XPS and XANES analyses. Wear 254: 863-870 ( 2003)

[11] Muraki M, Wada H. Influence of the alkyl group of zinc dialkyldithiophosphate on the frictional characteristics of molybdenum dialkyldithiocarbamate under sliding conditions. Tribol Int 35: 857-863 (2002)

[12] Muraki M, Yanagit Y, Sakaguchit K. Synergistic effect on frictional characteristics under rolling-sliding conditions due to a combination of molybdenum dialkyldithiocarbamate and zinc dialkyldithiophosphate. Tribol Int 30: 69-75 (1997)

[13] Feng X, Xia Y. Tribological properties of gray cast iron lubricated using organic compounds containing Mo and ZnDTP additives. Lubr Sci 24: 153-164 (2012)

[14] Francoa C M, Clarkeb P J, Tateb M E, Oadesb J M. Hydrophobic properties and chemical characterisation of natural

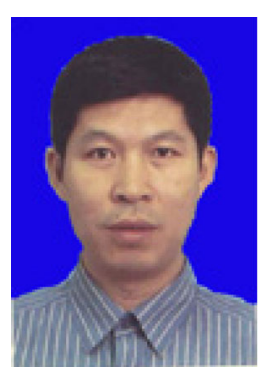

Yanqiu XIA. He received his MS and Ph.D degrees in mechanical engineering from Shenyang University of Technology and Northeastern University, China, in 1993 and 1999, respectively. He joined the School

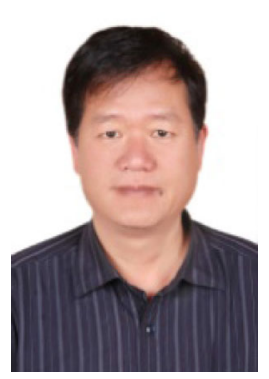

Guoxiong CHEN. He received his MS and Ph.D degrees in plant science from Ben-Gurion University of the Negev and University of Haifa, Israel, in 2000 and 2005 respectively. He joined the Cold and Arid Regions water repellent materials in Australian sands. $J$ Hydrol 231-232: 47-58 (2000)

[15] Cornelia P V, Nastold P, Jetter R. Homologous very-long-chain 1,3-alkanediols and 3-hydroxyaldehydes in leaf cuticular waxes of Ricinus communis L. Phytochemistry 62: 433-438 (2003)

[16] Ji X F, Jetter R. Very long chain alkylresorcinols accumulate in the intracuticular wax of rye (Secale cereale L.) leaves near the tissue surface. Phytochemistry 69: 1197-1207 (2008)

[17] Xu S, Jiang P, Wang Z, Wang Y. Crystal structures and chemical composition of leaf surface wax depositions on the desert moss Syntrichia caninervis. Biochem Syst Ecol 37: 723-730 (2009)

[18] Samuels L, Kunst L, Jetter R. Sealing plant surfaces: cuticular wax formation by epidermal cells. Plant Biol 59: 683-707 (2008)

[19] http://www.srdata.nist.gov.xps

[20] Xia Y, Wang L, Liu X, Qiao Y. Tribological properties of phosphor bronze and nanocrystalline nickel coatings under $\mathrm{PAO}+\mathrm{MoDTC}$ and ionic liquid lubricated condition. Tribol Lett 31: 149-158 (2008)

of Energy Power and Mechanical Engineering, North China Electric Power University from 2010. His current position is a professor. His research areas cover tribology of mechanical and electrical equipment, focusing on lubricants, greases, additives and tribochemistry.

Environmental and Engineering Research Institute, Chinese Academy of Sciences from 2008. His current position is a professor in the Institute. His research areas cover plant physiology and genetics, focusing on plant leaf cuticle chemistry, physics, physiology, and genetics. 